\title{
SUBJETIVIDADES
}

Estudo Teórico

e-ISSN: 2359-0777

\section{A ARTE URBANA E SEUS EFEITOS NOS PROCESSOS DE SUBJETIVAÇÃO: UMA REVISÃO BIBLIOGRÁFICA NO CAMPO DA PSICOLOGIA}

\author{
The Urban Art and its Effects on Subjective Processes: A Bibliographic Review in Psychology Field
El Arte Urbana y sus Efectos en los Procesos de Subjetividad: Una Revisión Bibliográfica en el Campo de la Psicología

\section{L'art Contemporain et ses Effets sur les Processus de Subjectivation: Un Examen Bibliographique dans la Biscipline de la Psychologie}

DOI: $10.5020 / 23590777 . r s . v 17 i 2.5454$

\author{
Ana Maria Rolim Sodré \\ Acadêmica em psicologia.
}

\section{Lílian Weber (Lattes)}

Psicóloga. Doutora e mestre em administração com ênfase em gestão de pessoas, na linha de pesquisa "Gestão, trabalho e subjetividade". Professora de graduação e pós-graduação.

\section{Resumo}

\begin{abstract}
Na contemporaneidade, equipes multidisciplinares têm pensado em formas de reinventar as cidades para os cidadãos, transformando os espaços em lugares onde ocorram entrelaçamento social e humanização dos sujeitos. Assim, o espaço urbano tornou-se foco de intervenções, dentre elas a arte, que sai de museus e ganha as ruas. A arte urbana configura-se como uma prática social que envolve aspectos estéticos e significados sociais, afetando o cotidiano vivido pelos moradores das grandes cidades. Os efeitos da arte urbana nos processos de subjetivação constituem o pano de fundo deste artigo, que tem como objetivo analisar a produção acadêmica que articula arte urbana e psicologia. Para tanto, foi realizada uma revisão sistemática da literatura em artigos, publicados nas bases de dados PePsic e Scielo, no período de 2006 a 2015. Poucas foram as publicações encontradas relacionando arte urbana e psicologia. A relação da psicologia com a arte, conforme indicam as publicações do período, está atrelada à esfera terapêutico-clínica e à relação artista-obra. A relação de afetação naqueles que contemplam a obra é pouco explorada no campo da psicologia. Pensar nessa afetação, em particular na esfera pública, traria contribuições para desenvolver intervenções coletivas incidindo nos processos de subjetivação. Observa-se a existência de uma lacuna nesse campo do saber, sendo indicado o desenvolvimento de investigações acerca da interrelação da psicologia com a arte por seus efeitos na (re)invenção dos sujeitos e na produção de modos de vida.
\end{abstract}

Palavras-chave: psicologia; arte; subjetividade; arte urbana; grafite.

\section{Abstract}

Currently, multidisciplinary teams have been thinking of ways to reinvent cities for citizens, transforming the environment in places where social interweaving and humanization of individuals occur. The urban environment becomes the focus of interventions, among them the art leaving museums and gains streets. Urban art is configured as a social practice that involves aesthetic and social significance, affecting the daily life experienced by residents in large cities. The effects of urban art in subjective processes are the background of this article, which aims to analyze the academic production that articulates urban art and psychology. Therefore, a systematic review of literature was conducted, in articles published in PEPSIC and Scielo databases, in the period of 2006 and 2015. There are few publications found link: ing urban art and psychology. The relation of psychology to art, as shown by the publications of the period, is link: ed to clinical treatment sphere and the relation artist-work. The relationship between those who contemplate and the work of art is little explored in the field of 
psychology. In particular, think this affectation in the public sphere would develop contributions to collective interventions focusing on subjective processes. That demonstrates the existence of a gap in this field of knowledge, highlighting the importance of researches on this interrelationship due to its effects on the (re) invention of individuals and production of lifestyles.

Keywords: psychology; art; subjectivity; urban art; graffiti.

\section{Resumen}

En la actualidad, equipos multidisciplinarios han pensado formas de reinventar las ciudades para los ciudadanos, transformando espacios en lugares donde se producen lazos sociales y humanización de los sujetos. El espacio urbano se convierte en el foco de intervenciones, dentro de ellas el arte, que sale de museos y gana las calles. El arte urbana se entiende como una práctica social que envuelve aspectos estéticos y significados sociales, que afecta lo vivido actualmente por los residentes en las grandes ciudades. Los efectos del arte urbana en los procesos de subjetividad constituyen la tela de fondo de este artículo, que tiene como objetivo analizar la producción académica que une el arte urbana y la psicología. Por lo cual, fue realizada una revisión sistemática de la literatura, en artículos publicados en las bases de datos PePsic y Scielo, entre el periodo de 2006 al 2015. Pocas fueron las publicaciones encontradas que relacionaban el arte urbana y la psicología. La relación de la psicología con el arte, según indican las publicaciones del periodo, está relacionada al aspecto terapéutico-clínico y a la relación artista-obra. La relación de afectación en aquellos que contemplan la obra es poco explorada en el campo de la psicología. En particular, pensar en esta afectación en el aspecto público traería contribuciones para desarrollar intervenciones colectivas incidiendo en los procesos de subjetivad. Demostrándose, con eso, la existencia de una laguna en este campo del saber, lo que lleva al desarrollo de investigaciones acerca de esta interrelación por sus efectos en la (re)invención de los sujetos y en la producción de modos de vida.

Palabras clave: psicologí; arte; subjetividad; arte urbana; grafiti.

\section{Résumé}

Dans la contemporanéité, des équipes multidisciplinaires pensent à des manières de réinventer les villes pour les citoyens, en transformant des espaces dans des lieux où il se produise l'entrelacement social et l'humanisation des sujets. L'espace urbain devient ainsi le centre des interventions, dont celles centrées sur l'art, qui quitte les musées pour gagner les rues. L'art urbain se présente comme une pratique sociale impliquant des aspects esthétiques et des significations sociales, qui agit sur le quotidien vécu par les habitants des grandes villes. Les effets de l'art urbain sur les processus de subjectivation constituent la toile de fond de cet article, dont l'objectif est celui d'analyser la production scientifique associant l'art urbain et la psychologie. Pour cela, il a été effectué une revue systématique des articles publiés sur les bases de données PePsic et Scielo dans la période allant de 2006 à 2015. Peu de publications mettant en lien l'art urbain et la psychologie ont été retrouvées. Les rapports de la psychologie à l'art, comme il est indiqué par les publications de cette période, se concentrent sur les domaines clinical thérapeutique et de la relation artiste-œuvre. Les effets sur les spectateurs des œuvres sont encore peu explorés par la psychologie. En particulier, la réflexion sur ces effets dans l'espace public apporterait des contributions pour développer des interventions collectives ayant des incidences sur les processus de subjectivation. Il est démontré, ainsi, l'existence d'un déficit dans ce domaine du savoir et il est indiqué le développement de recherches portant sur cette interrelation en fonction de ses effets sur la (ré)invention des sujets et sur la production de modes de vie.

Mots-clés: psychologie; art; subjectivité; art urbain; graffiti.

O presente artigo tem como objetivo analisar a produção acadêmica que articula arte urbana (visual) e psicologia. $\mid \mathrm{O}$ interesse nesse objeto sustenta-se no desejo de conhecer o que a psicologia, no que tange à perspectiva de produção de subjetividade (Guattari \& Rolnik, 1999), tem a dizer sobre os efeitos da arte que, democraticamente, tem sido disponibilizada em espaços públicos e a céu aberto, no bojo das cidades.

Percebe-se que, com o passar do tempo, a ocupação das cidades vem acontecendo de forma utilitária, limitando possibilidades mais amplas de conviver com o contexto. As cidades poderiam ser palco de expressão da personalidade de seus moradores (Silva, 2014), pois é na relação que as pessoas estabelecem com o espaço urbano, em sua apropriação, que se apropriam de si mesmas.

Atualmente, equipes multidisciplinares têm pensado no espaço urbano, sua relação com as pessoas e em formas de reinventar as cidades, transformando espaços em territórios onde ocorram o entrelaçamento social e a humanização dos sujeitos. Do ponto de vista de Ribeiro (2009), o território é composto de aspectos materiais e imateriais, um campo de forças que produz singularidades. “É um lugar compartilhado no cotidiano, criador de raízes, laços de pertencimento e símbolos” (Ribeiro, 2009, p. 26). 
Nas relações sociais são produzidos o "pertencimento e estranhamento, assim como relações de dominação e exploração através do espaço pela apropriação/expropriação de seus recursos" (Porto-Gonçalvez, 2006, p. 288). Assim, arquitetos, urbanistas, paisagistas, planejadores urbanos em geral e, em alguns casos, o poder público, unem-se no propósito de que as cidades sejam usufruídas por seus habitantes, e não por conglomerados de prédios, popularmente chamados de "selva de pedra", ou pistas de alta velocidade para veículos produtores de um trânsito caótico (Antunes, 2011). O atual modelo de cidade foi se consolidando sob as premissas da revolução industrial. "O pseudoplanejamento urbano implacável, simplista e o pseudodesenho urbano que temos atualmente, é uma forma de desconstruir cidades" (Jacobs, 2009, p. 454).

Assim, o intuito de repensar o modelo urbano visa priorizar a qualidade de vida, por meio de projetos urbanísticos, transportes alternativos e áreas de convivência. A qualidade de vida está ligada ao bem-estar biopsicossocial, o qual, por fim, resulta em saúde em sua concepção mais ampla. Uma das pioneiras na reflexão entre a relação das pessoas com a cidade foi ma psicóloga Ingrid Gehl. Acompanhando o trabalho de seu marido, o arquiteto Jan Gehl, ela questionou sobre os desenhos de seus projetos: "Por que vocês, arquitetos, não estão interessados em pessoas? Vocês estão muito interessados em formas, mas vocês não sabem nada sobre as pessoas" (Antunes, 2011, p.1). A partir daí, eles passaram a estudar profundamente esse entrelaçamento entre arquitetura, psicologia e sociologia. "Isso se desenvolveu em meus quase 50 anos de devoção para estudar cidades para as pessoas", comentou Jan Gehl (Antunes, 2011, p.1). Os espaços em geral, incluindo os espaços urbanos especificamente, configuram-se como elementos no processo de produção de subjetividades.

É sempre por meio de imagens e formas que percebemos, compreendemos, criamos e nos comunicamos (Ostrower, 1995). Desde os primórdios da humanidade qo homem faz uso de imagens como forma de comunicação. As primeiras imagens pintadas em cavernas ajudavam o homem a se organizar coletivamente, e essa união também o ajudou a subsistir (Aragão, 2015). Por existir reciprocidade entre pessoas e ambiente, é fundamental o estudo do espaço urbano como produtor de subjetividade. Neste cenário, adiciona-se outro elemento, a cidade enquanto substrato para o fazer artístico. É muito comum a concepção da arte exposta em museus, mas a arte não se resume a isso, e observa-se uma tendência em tornar a arte pública e mais acessível.

Não há consenso acerca do que é a arte, pois todas as tentativas de definição já registradas se revelaram insatisfatórias tendo em vista que ela muda ao longo do tempo. Mesmo assim, é importante conceituar minimamente o que é arte, arte pública e arte urbana. Neste sentido, Weitz (1956, p. 6) defende que o conceito de arte é aberto e que "é logicamente impossivel garantir qualquer conjunto de propriedades definidoras". Para Axt, Tarouco e Shuch (2003), a arte não é apenas o universo das formas, mas também, e principalmente, o mundo das sensações de diferentes intensidades e fluxo num contínuo devir de inquietação. E é das sensações que a arte produz, sendo ela própria sensação em si mesma, que Deleuze e Guatarri (2007, p. 213) dizem: "o que se conserva, a coisa ou obra de arte, é um bloco de sensações, isto é, um composto de perceptos e afectos".

A arte pública é a arte que foi previamente autorizada pelo poder público para instalar-se nos espaços públicos, muitas vezes por encomenda dele (Marzadro, 2013). Pode também ser inserida na paisagem a partir de iniciativas privadas, e seu desenvolvimento está contextualizado na história da arte. Para Pallamin (2000, p. 24), "a arte urbana é uma prática social. Suas obras permitem a apreensão de relações e modos diferenciais de apropriação do espaço urbano, envolvendo em seus propósitos estéticos e trato com significados sociais que as rodeiam". Assim, a arte urbana pode redefinir o lugar e as experiências ali vivenciadas, o que vai muito além do estético. A intervenção urbana é uma vertente da arte urbana e interfere numa dada situação para promover alguma transformação ou reação, no plano físico, intelectual ou sensorial. Ela pode ser permanente ou efêmera.

No caso deste artigo, a arte urbana, a arte pública e as intervenções urbanas são objetos de interesse devido à sua potência em produzir modos de subjetivação, afetando os sujeitos em suas vidas cotidianas. Muitas são as marcas espalhadas pelas cidades, as quais são preenchidas por signos e imagens. Segundo Carlos (2007, p. 50), "os sinais emitem ordem: Beba Coca Cola, Fume Marlboro, Compre um Mazda, Use Nike..., Ande (farol verde), Pare (vermelho), Diminua o passo (amarelo), proibido estacionar, proibido virar à esquerda, etc.". Tudo isso contribui para direcionar as pessoas a consumirem os signos, na medida em que torna os objetos algo mágico, especial, de forma que passam a fazer parte do sonho das pessoas, redefinindo hábitos e suas relações com os objetos - produzindo realidades.

Bachelard (2008, p. 221) diz que "o ser é sucessivamente condensação que se dispersa explodindo e dispersão que reflui para o centro. O exterior e o interior são ambos íntimos". Nesse caso, pode-se pensar no efeito do grafite, que é concebido por Ferreira (2011) como sendo uma arte contemporânea, popular, feita em espaços externos no âmbito da cidade e sobre o mobiliário urbano: paredes, muros, placas ou outros aparatos de sinalização. Segundo o autor, ela é transgressora - do ponto de vista da autorização do seu fazer -, por transitar entre os limites do público e do privado para se expressar e provocar uma reflexão.

Assim, a cidade habita os sujeitos tal qual eles habitam a cidade, como bem escreve Mario Quintana em sua obra O Mapa: "Olho o mapa da cidade como quem examinasse a anatomia de um corpo (é nem que fosse meu corpo)..." (Alves, 2006, p. 115). Para que as pessoas se apropriem da cidade que habita nelas, o espaço não deve ter um sentido meramente funcional, mas precisa ser um resumo da vida e das experiências públicas e íntimas. A apropriação contínua e dinâmica do espaço poderá garantir a estabilidade de sua própria identidade (Pol, 1992). 
Todavia, o que se percebe é que as pessoas se submetem ao tempo que o relógio estabelece, de acordo com as prioridades do cotidiano. A problemática do tempo aparece exacerbadamente, pois o desenvolvimento impõe que se ganhe tempo (Lyotard, 1990). Assim, as pessoas estão vivendo rotinas cada vez mais aceleradas. Antigamente, o poder produzia freios: muralhas, fortalezas, sistemas fortificados, obstáculos, trincheiras, e também normas, interdições, etc. No entanto, no século XIX, passou-se da idade do freio à idade do acelerador (Pelbart, 1993), De forma que uma das maiores dificuldades humanas é não perceber o que sempre está ao seu redor. "Sofremos porque não vemos o valor do que está diante de nós e suspiramos, muitas vezes injustamente, pelas atrações imaginárias de outro lugar" (De Botton \& Armstrong, 2014, p. 59). O autor diz que isso se dá pela tendência humana de se acostumar às coisas e de se habituar. $O$ comportamento passa a ser automático justamente por causa do hábito, que exige maior atenção, sobrepujando os cinco sentidos. Apesar de atualmente haver mais liberdade corporal e uma comunicação mais veloz do que no passado, as pessoas estão mais conectadas e também mais isoladas. Percebe-se, muitas vezes, que a aproximação maior entre os sujeitos se dá por meios virtuais, como a telefonia móvel (Sant'Anna, 2005).

A arte urbana situa-se na contramão da essência da velocidade por estimular a experiência do espaço, pois uma alternativa à visita ao museu pode ser um passeio pelos itinerários urbanos (Peixoto, 1999), fluídos e (des)territorializados. Nesse processo, "as obras de arte urbana são, de certa forma, fruto ou produto do território, mas, ao mesmo tempo, incide sobre este mesmo território resignificando-o" (Marzadro, 2013). Podemos ressignificar os espaços da cidade por intermédio da arte, tornando-os afetivos e subjetivos, promovendo o enlaçamento social. "As ruas são o apartamento do coletivo. O coletivo é um ser constantemente em movimento, sempre agitado, que vive, experimenta, conhece e inventa tantas coisas entre as fachadas dos imóveis quanto o faz o indivíduo no abrigo de suas quatro paredes." (Benjamin, 1989, p. 441). Sim, o coletivo é agente transformador em movimento, e com vivências plenas de pertencimento e apropriação.

As permanentes ressignificações fazem com que as pessoas se apropriem cada vez mais desses espaços, pois "observar a arte não significa 'consumi-la' passivamente, mas tornar-se parte de um mundo ao qual pertencem essa arte e esse espectador. Olhar não é um ato passivo; ele não faz que as coisas permaneçam imutáveis.” (Archer, 2001, p. 235).

É justamente a análise do modo como cada sujeito se relaciona com os signos próprios à sua época, da maneira como cada vida experimenta o conjunto de regras que define sua sociedade, que nos apontará dados para a compreensão dos processos de subjetivação (Gonçalves, 2007). Podemos considerar a produção de subjetividade como o conjunto de condições que torna possível que instâncias individuais e coletivas, corporais ou não, estejam aptas a emergir como território existencial. A autora cita Guattari (1992) ao pensar a subjetivação como um processo de agrupamento, de composição, de agenciamentos heterogêneos de corpos, práticas, juízos e técnicas.

\section{Método}

A pesquisa foi realizada através de uma revisão integrativa da literatura, que consiste em uma revisão estruturada e metódica visando responder uma questão, com estabelecimento de critérios de inclusão e exclusão e análise cuidadosa dos resultados. Para Gomes e Caminha (2014, p. 396), a revisão sistemática (integrativa), também chamada de síntese criteriosa, tem sido considerada como uma "opção para não apenas acastelar informações, mas acompanhar o curso científico de um período específico, chegando ao seu ápice na descoberta de lacunas e direcionamentos viáveis para a elucidação de temas pertinentes".

A presente pesquisa foi realizada entre abril e maio de 2016, através de uma busca por artigos indexados nas bases de dados Scielo e PePsic, a fim de verificar a incidência de publicações referentes à articulação entre arte urbana (visual) $e$ psicologia, no período de 2006 a 2015. Além do enquadre temático, utilizou-se como critérios de inclusão na análise os seguintes aspectos: artigo em língua portuguesa e artigo disponível na íntegra.

Utilizando os termos associados, foi encontrado apenas um artigo na BVS - Psi e nenhum artigo nas bases Scielo e Pepsic. $\mathrm{O}$ artigo encontrado se refere à relação entre arte e práticas educativas, de modo que não se enquadrava nos propósitos da investigação.

Dessa forma, optou-se por ampliar o campo de pesquisa, buscando investigar a existência de outras formas de nominar o tema (outros descritores) e outras articulações entre a arte e a psicologia. Foram usados descritores isolados para, na leitura dos títulos e resumos, realizar a avaliação da adequação do artigo aos propósitos deste estudo. Os descritores utilizados foram: arte; arte-terapia; cidade e grafite.

Foram incluídos na análise artigos que articulavam psicologia e arte, assim como arte e modos de subjetivação. Foram definidos critérios de exclusão, de modo a possibilitar a circunscrição do tema. Ficaram fora da análise final artigos relacionando arte e outras áreas do saber; artigos referindo outras expressões artísticas que não as visuais (por exemplo: musica e teatro); artigos de análise de práticas artísticas; artigos referentes à interpretação de obras de arte; artigos sobre a mercantilização da arte. Os artigos que englobavam psicologia e arte foram lidos para possibilitar a compreensão dessa articulação e para chegar a um possível entendimento do objeto mais restrito, isto é, a ligação entre arte urbana e processos de subjetivação. 


\section{Resultados}

Foram encontrados 50 (cinquenta) artigos que abordavam o entrelaçamento entre arte e psicologia. Tais artigos foram categorizados da seguinte forma: artigos (17) sobre arteterapia; artigos (9) sobre arte e psicanálise; artigos (13) sobre arte e seus efeitos no artista que a faz; e artigos (11) sobre arte e seus efeitos em quem a contempla.

Os autores dos artigos que abordam arteterapia (Sato \& Mesquita, 2015; Zanchet, Palombini \& Yasui, 2015; Corrêa, 2014; Reis, 2014; Liberato \& Dimenstein, 2013; Lima et al., 2013; Testa, 2012; Azevedo \& Miranda, 2011; Valladares \& Silva, 2011; Coqueiro, Vieira \& Freitas, 2010; Fonseca, Thomazoni, Lockmann \& Butkus, 2009; Machado, Feres-Carneiro \& Magalhães, 2008; Lima \& Pelbart, 2007; Vasconcelos \& Giglio, 2007; Castro \& Lima, 2007; Lima, 2006) buscaram realizar uma reflexão por meio de um projeto que utiliza a arte como instrumento potencializador para o processo de humanização e melhoria no acolhimento em um serviço de saúde. Ao referidos autores compreendem a arte como um instrumento para trabalhar com a (inter) subjetividade e como dispositivo para melhoria da saúde e do bem-estar, tendo se mostrado um importante instrumento e sendo cada vez mais utilizada por profissionais da área da saúde mental.

Nesse sentido, é mencionado com frequência o reconhecido trabalho da psiquiatra Nise da Silveira que, através das artes expressivas, transformou os atendimentos de doentes mentais internados em um grande hospital psiquiátrico, localizado no subúrbio da cidade do Rio de Janeiro na década de 40, e inspira até os dias de hoje trabalhos e estudos na área. Os autores buscam por meio das intervenção e de seus desdobramentos problematizar temas referentes ao cuidado, à educação e à promoção de saúde.

Partindo da referência de espaço liso e espaço estriado, proposto por Deleuze e Guatarri (2007) - os quais apresentam tais dicotomias, polos opostos, no campo social e político -, os autores do projeto salientam que o espaço liso é um espaço nômade, que se refere aos fluxos e à produção de desejos instituintes, ligados à ideia do inesperado, do desconhecido, do inventivo, o que os autores franceses nomearão de rizoma, desterritorialização, fluxos e linhas de fuga. O espaço estriado é sedentário, refere-se aos estratos e forças instituídas pelo aparelho de Estado. Assim, os autores do projeto propuseram a montagem de um estande com insígnias do campo da saúde, tais como: jaleco, bloco de receituários, carimbo, pílulas, etc., compondo um setting terapêutico (Zanchet et al., 2015). Essas insígnias foram substituídas por algo lúdico, como a troca das pílulas por confeitos de chocolate coloridos. Por meio dessas linhas de fuga ou desterritorialização, concluíram que a arte e a pesquisa têm em comum a possibilidade de ajudar a olhar e ouvir para então compreendermos a realidade e nos afetarmo-nos por ela de maneira diferente.

Outra abordagem que tange a relação entre psicologia e arte diz respeito à análise da arte como modo de expressão de si. Nesta categoria, os estudos encontrados (Arruda, 2015; Stubs, Teixeira Filho, Galindo \& Milioli, 2015; Silva, 2015; Dabul \& Barreto, 2014; Providello \& Yasui, 2013; Hamann, Cardoso, Tedesco \& Pizzinato, 2013; Zanella, Levitan, Almeida \& Furtado, 2012; Furtado \& Zanella, 2009; Ceará \& Dalgalarrondo, 2008; Dupret, 2008; Bilbao \& Cury, 2006) indicam os efeitos da arte na produção da subjetividade de quem a produz. Interessante notar que são também esses efeitos que se mostram relevantes para o contexto da arte-terapia. A presente categoria foi separada por se tratarem de artigos que não estão relacionados ao contexto psiquiátrico ou do âmbito das patologias, como no primeiro caso.

Alguns artigos mencionam o efeito da expressão de si por meio da intervenção urbana, através da qual eles não somente protestam como também buscam reconhecimento social e diversão. No caso de um projeto de oficinas de arte como aprendizado para jovens, os pesquisadores viram nisso uma forma de estimular o pensamento criativo, a autonomia, a confiança em si mesmos e a reflexão, gerando o empoderamento desses sujeitos e "uma singularização existencial que coincida com um desejo, com um gosto de viver, com uma vontade de construir o mundo no qual nos encontramos, com a instauração de dispositivos para mudar os tipos de sociedade, os tipos de valores que não são os nossos" (Guattari \& Rolnik, 1999, p. 17). Há ainda uma dimensão que articula a oscilação entre o público e o privado, quando os artistas são confrontados com eventos marcadamente associados às expectativas culturais. "A única finalidade aceitável das atividades humanas é a produção de uma subjetividade que enriqueça de modo contínuo sua relação com o mundo" (Guattari, 1992, p. 33).

No que diz respeito à articulação entre psicanálise e arte, os artigos encontrados (Faissol \& Poli, 2014; Poli \& Mesquita, 2014; Sousa, 2014; Soares \& Coelho, 2014; Sousa \& Ferreira, 2010; Falbo, 2010; Rivera, 2007, 2008; Andriolo, 2006) trazem com força o conceito de sublimação, mecanismo de defesa segundo o conceito freudiano. Os pesquisadores trazem, à luz dessa teoria, o quanto a sublimação é uma exigência da civilização para que o homem troque a satisfação pulsional - descarga sexual - direta, por uma satisfação que se dará pela via indireta do trabalho na própria cultura. Trocando por atividades humanas socialmente avalizadas, que não estão relacionadas aparentemente à sexualidade, mas cuja origem só é possível a partir da pulsão sexual.

Assim, o sublime designa, no campo da estética, um sentimento vinculado a ideia de grandiosidade, ao passo que, para a psicanálise, é um mecanismo psíquico com a finalidade de mudar os objetivos da pulsão sexual. Segundo Estevam (2009), "a sublimação é essa capacidade que tem o instinto sexual de renunciar ao seu objetivo imediato em troca de outros objetivos não sexuais e mais apreciados pela sociedade". O sujeito passa a erotizar outras esferas da existência. Nos artigos dessa 
categoria, foram encontradas análises com relação à arte urbana considerando positivamente sua possibilidade enquanto micro-resistência ao empobrecimento das vivências urbanas devido à espetacularização das cidades. Assim, "qualquer lugar pode transformar-se em espaço de arte, o que gera forte realidade com o mundo real e anula a diferença entre o espaço de vida e o outro da arte... fazendo dos cidadãos, muitas vezes, passantes ocasionais surpreendidos pela ação, alguns públicos de arte" (Silva, 2014). Numa sociedade capitalista que, muitas vezes, insiste em transformar a arte em mercadoria, a arte urbana faz um caminho inverso. "Para manter viva a luta da arte pela emancipação humana, torna-se necessário e urgente que o artista do presente busque mediar na experiência estética a tensão entre a realidade vivida e a vida social" (Reis, 2014, p. 7).

Por fim, a categoria "arte para quem contempla" (Stubs, Teixeira Filho \& Peres, 2014; Barroco \& Superti, 2014; Meira, 2013; Ribeiro, 2013; Tardivo, 2012; Favaretto, 2011; Tavares, 2010; Britto \& Jacques, 2009; Dabul, 2008; Furtado \& Zanella, 2007; Ivo, 2007) engloba os artigos mais próximos ao interesse inicial da presente pesquisa, embora nem sempre o enquadre fosse a arte urbana. Nesses artigos, a arte além de representar a realidade, também cria novas realidades, com outros relevos. Dessa forma ela se configura potencialmente como um disparador de modos de subjetivação singularmente plurais; subjetividades tecidas de compostos traços múltiplos nos quais o eu e o outro o são em diferença e unidade. É provocando que essas obras disparam outras linhas de subjetivação (Stubs et al., 2014).

Jamais a arte se propõe a ser homogeneizadora e, no espaço público, ela é fonte criadora e mantenedora de tensões, configurando potência de micro-resistência, embora também organize a experiência do entorno e as experiências dos sujeitos que nela se implicam. Não cabe à arte se ajustar fielmente ao contexto, mas permitir a circulação e o deslocamento de sentidos em torno dela, estimulando por provocar o contexto para novas significações do espaço. $O$ ser humano atinge a plenitude à medida que se apodera das experiências alheias e, ao mesmo tempo, o que ele sente como seu passa a pertencer à humanidade como um todo. Desse modo, a arte é o meio indispensável para a união do indivíduo com o todo, já dizia Fischer (1976). Operando por meio de signos e símbolos, a arte pode trazer transformações para as funções psicológicas específicas, promovendo uma nova organização psíquica ao indivíduo, considerando que oportuniza a vivência indireta de emoções e sentimentos e das relações sociais. A experiência estética é da ordem do conhecer, expressar e fazer, sendo a partir da percepção que a experiência estética tem lugar, entrelaçando a objetividade e a subjetividade ao mundo externo e ao mundo interno (Tardivo, 2012). Definitivamente, a arte afeta o expectador que a contempla.

\section{Considerações Finais}

À guisa de considerações finais, pode-se dizer que o mapeamento dos artigos que articulam psicologia e arte permite ratificar que há, indiscutivelmente, um efeito da arte sobre a psique humana, contribuindo para a saúde mental. Entretanto, observa-se que há uma concentração das publicações que tratam dos efeitos da arte sobre a patologia e a análise individualizante de seus efeitos. Poucos foram os artigos que abordavam a arte urbana e seus efeitos nos sujeitos que a observam ou a contemplam. Portanto, não é mostrado interesse acadêmico diante do potencial efeito que a arte urbana possui nos modos de subjetivação, demonstrando a existência de uma lacuna neste campo do saber.

, Assim sendo, é indicado o desenvolvimento de investigações acerca dos efeitos da arte urbana visual, pública, na (re) invenção dos sujeitos e na produção de modos de vida. Se é indiscutível o efeito da arte sobre a psique, pode-se pensar a potência da alteração dos cenários de concreto das cidades, transformadas em suportes para a arte, com suas cores, formas, provocações. Caberia pensar nas intervenções urbanas como possibilidade de prevenção em saúde mental.

O panorama apresentado indica a necessidade de seguir investigando sobre o alcance que a arte de rua tem sobre aqueles que habitam as cidades, bem como as possibilidades de apropriação e contemplação dela em cotidianos marcados pela aceleração e pela redução da disponibilidade em estar atento ao entorno. Tendo em vista que a arte urbana encontrase em locais abertos, os denominados espaços urbanos, onde todos têm acesso, espera-se que seus efeitos subjetivantes também sejam mais amplos, em maior escala e repercussão, especialmente nas grandes cidades. Com este artigo procuramos contribuir para as discussões referentes ao tema, no intuito de ampliar a perspectiva, o aprofundamento do conhecimento, e a valorização da prática da psicologia social e ambiental.

\section{Referências}

Alves, J. E. L. (2006). Mario Quintana: Cotidiano, lirismo e ironia. Canoas, RS: Ed. Ulbra.

Andriolo, A. (2006). O método comparativo na origem da psicologia da arte. Psicol. USP, 17(2), 43-57. 
Antunes, B. (2011, Dezembro). Jan Gehl fala sobre cidades e escala humana. Revista AU Arquitetura e Urbanismo, 215. Link

Aragão, S. R. (2015). A arte como expressão de sentimentos e catarse emocional nos processos terapêuticos. Obvious. Link Archer, M. (2001). Arte contemporânea: Uma história concisa. São Paulo: Marins Fontes.

Arruda, L. (2015). Translesbianizando o olhar: Representações na margem da arte. Rev. Estud. Fem., 23(1), 229-238. Link

Axt, M., Tarouco, L. M. R., \& Shuch, E. M. M. (2003). Linhas de fuga no processo artístico com a tecnologia digital. Renote, 1(1). Link

Azevedo, D., M., \& Miranda, F. A. N. (2011). Oficinas terapêuticas como instrumento de reabilitação psicossocial: Percepção de familiares. Esc. Anna Nery, 15(2), 339-345. Link

Bachelard, G. (2008). A poética do espaço (2. ed.). São Paulo: Martins Fontes.

Barroco, S. M. S., \& Superti, T. (2014). Vigotski e o estudo da psicologia da arte: Contribuições para o desenvolvimento humano. Psicologia e Sociedade, 1(23), 22-31.

Benjamin, W. (1989). Obras escolhidas III: Charles Baudelaire, um lírico no auge do capitalismo. São Paulo: Brasiliense.

Bilbao, G. G. L., \& Cury, V. E. (2006). O artista e sua arte: Um estudo fenomenológico. Paidéia, 16(33), 91-100.

Britto, F. D., \& Jacques, P. B. (2009). Corpocidade: Arte enquanto micro-resistência urbana. Fractal, Rev. Psicol., 21(2), 337-349.

Carlos, A. F. A. (2007). O espaço urbano: Novos escritos sobre a cidade. São Paulo: FFLCH.

Castro, E. D., \& Lima, E. M. F. A. (2007). Resistência, inovação e clínica no pensar e no agir de Nise da Silveira. Interface, 11(22), 365-376, 2007.

Ceará, A. T., \& Dalgalarrondo, P. (2008). Jovens pichadores: Perfil psicossocial, identidade e motivação. Psicol. USP, 19(3), 277-293.

Coqueiro, N. F., Vieira, F. R. R., \& Freitas, M. M. C. (2010). Arteterapia como dispositivo terapêutico em saúde mental.Acta Paul. Enferm., 23(6), 859-62. Link

Corrêa, M. C. M. R. (2014). Oficina Terapêutica de Mosaico de Papel: O lugar da materialidade no campo da Terapia Ocupacional. Interface, 18(49), 431-441. Link

Dabul, L. (2008). Museus de grandes novidades: Centros culturais e seu público. Horiz. Antropol., 4(29), 257-278. Link

Dabul, L. \& Barreto, R. (2014). Fim de linha na arte: Pintores retratistas de rua. Mana, 20(1), 39-61. Link

De Botton, A., \& Armstrong, J. (2014). Arte como terapia. Rio de Janeiro: Intrínseca.

Deleuze, G., \& Guatarri, F. (2007). O que é a Filosofia? (5. ed.). Rio de Janeiro: Ed. 34.

Dupret, L. (2008). Subjetividade e arte de rua: 100\% Graffit. Psicol. Esc. Educ., 12(2), 413-421. Link

Faissol, K. R. M., \& Poli, M. C. (2014). Adolescer com arte. Trivum, 6(2), 128. Link

Falbo, G. (2010). O espaço vazio: Reflexões sobre a função do vazio na cura psicanalítica e na arte. Ágora, 13(1), 109-120. Link 
Favaretto, C. F. (2011). Deslocamentos: Entre a arte e a vida. $A R S, 9(18), 94-109$. Link

Ferreira, M. A. (2011). Arte urbana no Brasil: Expressões da diversidade contemporânea. São Paulo: Universidade Nove de Julho.

Fischer, E. (1976). A necessidade da arte. Rio de Janeiro: Zahar Editores.

Fonseca, T. M. G., Thomazoni, A. R, Lockmann, V., \& Butkus, V. (2009). Espaços heterotópicos, imagens sobrepostas: Encontros entre arte, loucura e memória. Psicol. Cienc. Prof., 29(2), 406-415. Link

Furtado, J. R., \& Zanella, A. V. (2007). Artes visuais na cidade: Relações estéticas e constituição dos sujeitos. Psicol. Rev., 13(2), 309-324. Link

Furtado, J. R., \& Zanella, A. V. (2009). Graffiti e cidade: Sentidos da intervenção urbana e o processo de constituição dos sujeitos. Rev. Mal-Estar Subj., 9(4), 1279-1302. Link

Gomes, I. S., \& Caminha, I. O. (2014). Guia para estudos de revisão sistemática: Uma opção metodológica para as ciências do movimento humano. Movimento, 20(1), 395-411.

Gonçalves, G. A. (2007). Inscrições urbanas: Uma cartografia dos processos de subjetivação envolvidos no graffiti. (Dissertação de Mestrado, Programa de Pós-Graduação em Psicologia). Pontifícia Universidade Católica de Minas Gerais, Belo Horizonte.

Guattari, F. (1992). Caosmose: Um novo paradigma estético. Rio de Janeiro: Ed. 34.

Guattari, F., \& Rolnik, S. (1999). Micropolitica: Cartografias do desejo. Petrópolis: Vozes.

Hamann, C., Cardoso, J. G. M, Tedesco, P. C., \& Pizzinato, A. (2013). Entre o público e o privado: Discurso de mulheres em movimentos de grafite. Ex Aequo, 28, 45-58. Link

Ivo, A. B. L. (2007). Cidade: Mídia e arte de rua. Cad. CRH, 20(49), 107-122. Link

Jacobs, J. (2009). Morte e vida de grandes cidades (2. ed.). São Paulo: Martins Fontes.

Liberato, M. T. C., \& Dimenstein, M. (2013). Arte, loucura e cidade: A invenção de novos possíveis. Psicol. Soc., 25(2), 272281. Link

Lima, E. M. F. A. (2006). Por uma arte menor: Ressonâncias entre arte, clínica e loucura na contemporaneidade. Interface, 10(20), 317-329. Link

Lima, E. M. F. A., \& Pelbart, P. P. (2007). Arte, clínica e loucura: um território em mutação. História, Ciências, Saúde, 14(3), 709-735. Link

Lima, M. C. P., Martins, K. P. H., Rocha, L. P., Parente Jr., P. A., Castro, I. P., Pinheiro, N. M., \& Domingues, M. (2013). Arte e mediação terapêutica: Sobre um dispositivo com adolescentes na clínica-escola. Rev. Mal-Estar Subj., 13(34), 775-796. Link

Lyotard, J. F. (1990). O inumano: Considerações sobre o tempo. Lisboa: Estampa.

Machado, R. N., Feres-Carneiro, T., \& Magalhães, A. S. (2008). Demanda clínica em psicoterapia de família: ArteDiagnóstico familiar como instrumento facilitador. Paidéia, 18(41), 555-566. Link

Marzadro, F. (2013). Espaço público arte urbana e inclusão social. Revista NAU Social, 4(6), 169-183. Link 
Meira, A. M. (2013). As crianças na cidade e o acompanhamento terapêutico. Psicol. Soc., 25(2), 41-45. Link

Ostrower, F. (1995). Acasos e criação artística (2. ed.). Rio de Janeiro: Campus.

Pallamin, V. M. (2000). Arte urbana: São Paulo: Região Central (1945-1998): Obras de caráter temporário e permanente. São Paulo: Annablume.

Peixoto, N. B. (1999). Intervenções Urbanas. Revista Rua, esp, 81-88.

Pelbart, P. P. (1993). A nau do tempo-rei: Sete ensaios sobre o tempo da loucura. Rio de Janeiro: Imago.

Pol, E. (1992). Seis reflexiones sobre los procesos psicologicos en el uso, organizacion y evaluacion del espacio. In M. Amérigo, J. I. Aragonés, \& J. Corraliza (Orgs.), El comportamiento en el medio natural y construido (pp.121-133). Badajoz, Orellana: Junta de Extremadura.

Poli, M. C., \& Mesquita, D. B. G. (2014). Arte \& Psicose: A obra de Arthur Bispo do Rosário. Psicol. Cienc. Prof., 34(3), 612624. Link

Porto-Gonçalvez, C. W. (2006). A globalização da natureza e a natureza da globalização (1. ed.). Rio de Janeiro: Civilização Brasileira.

Providello, G. G. D., \& Yasui, S. (2013). A loucura em Foucault: Arte e loucura, loucura e desrazão. História, Ciências, Saúde, 20(4), 1515-1529. Link

Reis, A. C. (2014). Arteterapia: A arte como instrumento no trabalho do Psicólogo. Psicol. Cienc. Prof., 34(1), 142-157. Link

Ribeiro, A. M. (2013). O corpo e o feminino enquanto lugares de subjetivação possível: O aporte das artes visuais. Ágora, 16(1), 87-103. Link

Ribeiro, M. T. F. (2009). Introdução. In M. T. F. Ribeiro, \& C. R. S. Milani (Orgs.), Compreendendo a complexidade socioespacial contemporânea: O território como categoria de diálogo interdisciplinar. Salvdor: EDUFBA.

Rivera, T. (2007). O sujeito na psicanálise e na arte contemporânea. Psicol. Clin., 19(1), 13-24. Link

Rivera, T. (2008). Ensaio sobre o espaço e o sujeito: Lygia Clark e a psicanálise. Ágora, 11(2), 219-238. Link

Sant'Anna, D. B. (2005). Corpos de passagem: Ensaios sobre a subjetividade contemporânea. São Paulo: Estação Liberdade.

Sato, M. A., \& Mesquita, J. R. C. (2015). Arte e humanização das práticas de saúde em uma Unidade Básica. Interface: Comunicação, Saúde, Educação, 19(55), 1027-1038. Link

Silva, A. (2014). Cidade para pessoas: Como Natália Garcia inventou uma empresa a partir de uma causa. Projeto Draft. Link

Silva, M. A. (2015). Abordagem sobre trabalho artesanal em histórias de vida de mulheres. Educ. Rev., 55, 247-260. Link

Soares, M. S., \& Coelho, D. M. (2014). Sobre o uso da sublimação como instrumento para uma metapsicologia da arte. Fractal, Rev. Psicol., 26(esp.), 593-606. Link

Sousa, E. L. A. (2014). A transgressão que salva. Rev. Latinoam. Psicopatol. Fundam., 17(3), 787-796. Link

Sousa, E. L. A., \& Ferreira, S. (2010). Marcas do abjeto na arte contemporânea. Tempo Psicanal., 42(1), 75-88. Link

Stubs, R., Teixeira Filho, F. S., \& Peres, W. S. (2014). A potência do cyborg no agenciamento de modos de subjetivação pósidentitários: Conexões parciais entre arte, psicologia e gênero. Fractal, Rev. Psicol., 26(3). Link 
Stubs, R., Teixeira Filho, F. S., Galindo, D., \& Milioli, D. (2015). Corpos, subjetivações estéticas e arte e feminismos: Passagens na pesquisa em Psicologia. Fractal, Rev. Psicol., 27(3), 211-218. Link

Tardivo, R. C. (2012). Uma perspectiva poética-crítica em psicologia da arte. Rev. Psicol. Polít., 12(23), 153-160. Link

Tavares, A. (2010). Ficções urbanas: Estratégias para a ocupação das cidades. ARS, 8(16), 21-30. Link

Testa, F. (2012). Uma discreta dança da resistência: Corpo, arte e subjetivação na oficina de criatividade de um hospital psiquiátrico. Interface, 16(40), 95-106. Link

Valladares, A. C. A., \& Silva, M. T. (2011). A arteterapia e a promoção do desenvolvimento infantil no contexto da hospitalização. Rev. Gaúcha Enferm., 32(3), 443-450. Link

Vasconcelos, E. A., \& Giglio, J. S. (2007). Introdução da arte na psicoterapia: Enfoque clínico e hospitalar. Estud. Psicol., 24(3), 375-383. Link

Zanchet, L., Palombini, A. L., \& Yasui, S. (2015). Receituário mais que especial: Uma intervenção urbana para pensar arte e pesquisa no contexto da Reforma Psiquiátrica. Interface, 19(55), 1039-1050. Link

Zanella, A. V., Levitan, D., Almeida, G. B., \& Furtado, J. R. (2012). Sobre reXistências. Rev. Psicol. Polít., 12(24), 247-262. Link

\section{Endereço para correspondência}

Ana Maria Rolim Sodré

Email: anasodre62@yahoo.com.br

Lílian Weber

Email: lilian.weber@fadergs.edu.br

Recebido em: 19/07/2016

Revisado em: 29/03/2017

Aceito em: 06/05/2017 